Gammaglobulin, while suppressing the overt features of infectious hepatitis, may not prevent infection and excretion of the causal agent (Ward and Krugman, 1962). Contacts given gammaglobulin should clearly be considered as being potentially infectious.

Gammaglobulin is expensive and there may be a large number of contacts of a single case. Accordingly it would be helpful if the course of an outbreak could be predicted at an early stage. The surveys show that the risk to contacts and hence the necessity for gammaglobulin may vary greatly in different situations, but though the course of each outbreak was analysed its duration and extent could not be reliably foretold at the outset. However, certain main trends were evident. A single case of infectious hepatitis in a day school was the sole case in as many as two-thirds of the schools ; in day schools in which further cases did occur the incidence was usually small. As might be expected the risk among the pupils judged to be in closest contact-for example, those in the same class-was increased. Where gammaglobulin is in short supply its most economical use in day schools would seem to be for the protection of close contacts. Though the number of trials made in institutions other than schools, and also the number of contacts, is small, the findings suggest that the risk to contacts in such locations is considerably greater than in day schools; note should be taken of the substantial incidence in mental hospitals and children's homes, in which control by other means is especially difficult. Gammaglobulin would seem to be particularly useful in such institutions.

The investigation was not concerned with the efficacy of gammaglobulin among home contacts. The findings do suggest, however, that its practical value would depend on whether it were feasible to give the gammaglobulin either before the home contacts had been infected or at least at an early stage of the incubation period.

Our thanks are due to the Blood Products Laboratory, Lister Institute, for advice about the gammaglobulin and for details of its preparation.

\section{REFERENCES}

Kekwick, R. A., and Mackay, M. E. (1954). Spec. Rep. Ser. med. Res Coun. (Lond.), No. 286

Kistler, P., and Nitschmann, H. S. (1962). Vox Sang (Basel), 7, 414.

Stokes, J., iun., Farquhar, J. A., Drake, M. E., Capps, R. B., Ward, C. S., jun., and Kitts, A. W. (1951). F. Amer. med. Ass., 147, 714.

Ward, R and Krugman, S. (1962). Progress in Medical Virology, edited by E. Berger and J. L. Melnick, vol. 4, p. 88. Basel and New York.

\title{
Infection Risks of Haemodialysis-Some Preventive Aspects
}

\section{A Report to the Public Health Laboratory Service by the Working Party on Haemodialysis Units*}

\begin{abstract}
Summary : Three aspects of haemodialysis are of special concern to the microbiologist : (1) the hepatitis risk, (2) shunt sepsis, and (3) the hygiene of the equipment used. It is suggested that the risks of infection and crossinfection in haemodialysis units may be diminished by several measures, including the avoidance of overcrowding the pationts, setting up codes of practice for the staff, topical disinfection of the patient's skin, and sterilization of equipment. In addition pathologists should emphasize to laboratory staff dealing with specimens from patients that these carry major risks to health.
\end{abstract}

\section{Introduction}

Intermittent haemodialysis for chronic renal failure is now being practised at 28 centres in Britain, and six more main units and two satellite units are in the planning stage. Bacteriologists in several Public Health Laboratory Service (P.H.L.S.) laboratories have been asked for guidance on problems associated with these units, but have found it difficult to obtain reliable information on which to base their advice. A P.H.L.S. working party with power to co-opt experts not in the Service has therefore been set up to study the microbiological aspects of haemodialysis. The working party is anxious to help in tackling some of the practical problems in this field. The following preliminary note on some of the issues that arise may be of use, particularly to laboratory colleagues.

* The working party comprised the following members of the P.H.L.S. staff: Dr. Yvonne E. Cossart, Dr. E. H. Gillespie, Dr. D. M. Jones, Dr. J. C. Kelsey, Dr. B. Moore (chairman and secretary), Dr. I. G Murray, Dr. Sheila Polakoff, Dr. G. C. Turner, and the following Murray, Dr. Dr. R. M. Stirland.

Reprints may be obtained from Dr. B. Moore at the Public Health Laboratory, Church Lane, Heavitree, Exeter.

\section{Some Technical Aspects}

The cellulose film membranes of the artificial kidney separate the two circulations concerned in the dialysis: (1) the patient's blood, which flows from the arterial limb of an arteriovenous shunt inserted into his forearm or leg, through the dialyser, and back into the patient by the venous limb of the shunt; and (2) the dialysing fluid, prepared from a concentrate and either (a) flowing through a Kiil or some type of coil dialyser to waste-that is, "single pass," (b) recirculating continuously in a coil for a given period and then being discarded and replaced as in the Travenol machine, or (c) flowing continuously through a coil and partially recirculating before being discarded, as in the Baxter Recirculating Single Pass machine.

The dialysing fluid may be prepared in bulk by dilution of a concentrate in a 500-litre plastic tank for single patient treatment or in very much larger tanks for multiple patient treatment. Alternatively, the use of proportioning pumps makes it possible to deliver in a closed system from a concentrate continuously prepared fluid that is controlled by bedside monitors.

The two types of dialyser are the flat-bed Kiil and various forms of presterilized single-use coils. The Kiil has many advantages, in addition to lower running costs. The current model has a blood volume of only up to $140 \mathrm{ml}$. compared with some of the earlier very large volume coils which required priming with donor blood. The low internal resistance and the small capacity of the blood compartments make a blood pump unnecessary except occasionally where a patient's vascular condition requires it. The Kiil can be used with Cuprophane cellulose membranes, which are thinner and in some respects more effective than the tubular cellophane membranes of coils. The drawbacks of the Kiil are that it takes some time ano expertise to rebuild, is more difficult to sterilize, and offers a somewhat greater risk of infection to the operator. 
Until 1960 the frequency of dialysis was restricted by the limited number of blood vessels available for cannulation in any given patient. Long-term haemodialysis was made possible by the development of the Teflon-Silastic arteriovenous shunt (Quinton, Dillard, and Scribner, 1960). The arterial and venous limbs of the shunt are inserted under local anaesthesia into the patient's forearm or leg. With twice-weekly dialysis the average life of each limb of the shunt is about eight months. This technique is practised in virtually all haemodialysis centres.

More recently, Brescia, Cimino, Appel, and Hurwich (1966) simplified the cannulation of forearm veins in patients undergoing long-term dialysis by creating surgically a permanent fistula between the radial artery and an adjacent vein. During dialysis the engorged veins resulting from this internal arteriovenous shunt are readily cannulated with 14-gauge thin-walled needles.

\section{Microbiological Aspects of Haemodialysis}

Three aspects of haemodialysis are of special concern to the microbiologist: (1) the hepatitis risk, (2) shunt sepsis, and (3) the hygiene of the equipment used.

\section{Hepatitis Risk}

Several outbreaks of hepatitis involving patients and staff of haemodialysis units and associated laboratory workers have now been described in various countries. Drukker, Alberts, Odé, Roozendaal, and Wilmink (1967) collected records of 40 cases from 19 centres, and Drukker, Jungerius, and Alberts (1968) had records of a further 71, 45 in patients and 26 in dialysis unit staff. Ringertz and Nyström (1967) analysed a series of 80 cases of hepatitis, all more or less closely related to haemodialysis and renal transplantation and reported in Stockholm hospitals during 1964-6.

Whether this "hepatitis" represents one entity or several is still quite uncertain.

(1) In some outbreaks infectious hepatitis virus has been thought to be the causal agent simply because the grouping of cases pointed to an infectious condition (Pendras and Erickson, 1966). The implication is that serum hepatitis can be transmitted only by injection. This was the view expressed in the authoritative Control of Communicable Diseases in Man (American Public Health Association, 1965). More recently, Krugman, Giles, and Hammond (1967) published evidence suggesting that serum hepatitis virus is infective by mouth, and Ringertz and Zetterberg (1967) reported a large outbreak of serum hepatitis in Swedish cross-country runners which they ascribed to infection through scratches or wounds of the leg.

(2) Ringertz and Melén (1966) considered that an outbreak among personnel associated with the haemodialysis unit in St. Erik's Hospital, Stockholm, was probably caused by serum hepatitis virus because $(a)$ the incubation period when this could be established was usually 60 to 110 days, $(b)$ no secondary cases occurred in the family environment of hepatitis patients, $(c)$ the disease was insidious in onset, and $(d)$ prophylactic immunoglobulin in fairly high dosage had little or no preventive effect. In their more recent analysis of the Stockholm outbreak, Ringertz and Nyström (1967) also concluded that the disease was probably serum hepatitis transmitted to the staff by inoculation of infected blood into scratches or
wounds of the hands.

(3) Some at least of the hepatitis episodes in dialysis units in Britain have not conformed to the clinical and epidemiological picture of serum hepatitis, but have been compatible with infectious hepatitis. In some patients, for instance, the onset has been fulminating, the incubation period very variable, and there has been some evidence of attenuation by immunoglobulin.

(4) It should be remembered that other viruses can give rise to liver disease. In particular, there are reports in the literature of hepatitis due to cytomegalovirus and the glandular fever agent being transmitted by blood transfusion (Smith, 1964; Kääriäinen, Klemola, and Paloheimo, 1966).

The long incubation period of virus hepatitis and our present inability to culture viruses of this group in vitro have greatly complicated the epidemiological study of dialysis unit outbreaks. The published accounts leave some doubt about how many of those affected have been diagnosed clinically and how many by, say, an abnormal transaminase test. It has also not always been clear how much hepatitis was occurring at the relevant time in other units at the hospitals concerned and in the local population. Certainly the evidence points strongly to blood as the main vehicle of infection. First, many of the patients concerned have been the recipients of multiple transfusions to combat the anaemia associated with chronic renal failure. Secondly, the likelihood of contamination with blood rather than with, say, faeces stands out as the most obvious characteristic of the dialysis unit environment. There is, however, no reason to doubt the possibility of blood-borne crossinfection with infectious hepatitis virus. The available evidence suggests to us that both serum hepatitis virus and infectious hepatitis have played a part in dialysis unit infections. It would be wise, therefore, to consider blood, faeces, urine, and pharyngeal secretions of dialysis unit patients as all potentially infective, and to take precautions accordingly.

\section{Shunt Sepsis}

Infection and clotting are the two main complications of the Teflon-Silastic shunt. Shaldon (1966) stressed that the combination of infection and clotting in the cannula called for the greatest care in declotting to prevent septic embolism. Fatal or non-fatal septic embolization to the lungs has been described by various authors (Dalla Rosa, Galanti, Ancona, Bruschi, and Confortini, 1967 ; McDonald, Friedman, Waterhouse, and Thomson, 1967). Stille, Brass, Hach, Renner, and Heintz (1967) described five cases of generalized staphylococcal infection, with four deaths, in patients undergoing dialysis, the symptoms of septicaemia coming on 27 to 75 days after insertion of the shunts. Notable necropsy findings were lung abscesses or suppuration round the arterial limb of the shunt. They thought the organisms causing shunt infections could be implanted when the shunt was first inserted, particularly where a haematoma formed, or could enter along the cannula track or lodge inside the cannula with the risk of further blood-borne spread.

Curtis (1967) reported seven shunt infections in a total of 16 patient-years' experience at the Fulham unit. The organisms most commonly isolated were coagulase-positive and coagulasenegative staphylococci. Other infections were caused by Gram-negative rods, notably Pseudomonas aeruginosa. Martin, Clunie, Tonkin, and Robson (1968) reported 78 episodes of shunt infection in 25 Edinburgh patients during a total of 293 patient-months of haemodialysis. On two occasions a haemolytic streptococcus caused shunt infection and septicaemia, and one shunt infection was ascribed to Ps. aeruginosa. Otherwise the great majority of their shunt infections were staphylococcal, and phage-typing indicated four-fifths of these to have been due to autoinfection from the patients' own carrier sites. All the staphylococcal shunt cross-infections that occurred were traced to other patients and not to the unit's medical or nursing staff. The role of staphylococci and of Ps. aeruginosa in shunt infections underlines the point that infection control in dialysis units cannot be divorced from that exercised in other wards of the associated hospital.

Brescia et al. (1966) claimed that the use of a permanent arteriovenous fistula for haemodialysis virtually eliminated the problem of local sepsis. One of their patients, however, died of bacterial endocarditis, a complication not known to be associated with the Teflon-Silastic shunt. 
When antibiotic therapy for shunt infections is contemplated, stress is laid on the need to take into account the effect of renal failure on the excretion of the antibiotic and whether the drug used is dialysable. Practical guidance on the use of antibiotics in patients with renal failure is given by Kunin (1967). Shaldon (1966) found that a single intravenous dose of $1 \mathrm{~g}$. of vancomycin produced an effective antistaphylococcal blood level that lasted a fortnight, as the drug was not removed by dialysis. Cloxacillin was also effective for staphylococcal sepsis but was excreted by the liver and was therefore given in a divided daily dose of $0.5 \mathrm{~g}$. Martin et al. (1968) used cloxacillin in doses of $2 \mathrm{~g}$. four-hourly combined with penicillin for the treatment of shunt infections and found this combination highly effective. The administration of gentamicin to patients undergoing haemodialysis was studied by Curtis, McDonald, and Weston (1967). Curtis and Eastwood (1968) discuss the administration of colistin to such patients and Eastwood and Curtis (1968) the use of carbenicillin.

\section{Hygiene of Haemodialysis Equipment}

Early bacteriological studies of haemodialysis equipment were published from Seattle by Sherris, Cole, and Scribner (1961). Originally the tank containing the dialysis fluid was held at $37^{\circ} \mathrm{C}$. and colony counts of Pseudomonas and Aerobacter species exceeded $10^{6}$ per ml. after a run of 12 to 18 hours. By more effective cleaning and disinfection procedures and by keeping the dialysis fluid at a temperature of $4^{\circ} \mathrm{C}$., they could reduce bacterial counts to fewer than $10^{4}$ organisms per $\mathrm{ml}$. More recently, discharging the dialysis fluid to waste after one pass through the Kiil dialyser has reduced contamination of the tank and made refrigeration unnecessary. When the bacterial count of dialysis fluid remains below about $10^{4}$ per ml. the patient is apparently unaffected. With counts of $10^{\circ}$ upwards the composition of the fluid may change significantly and bacterial metabolites diffuse across the membranes (Kidd, 1964), sometimes giving rise to severe reactions.

The likelibood of saprophytic organisms multiplying in dialyser circuits has recently been reduced by substituting for open storage plastic tanks proportioning pumps that provide a continual supply of dialysing fluid prepared in situ from a concentrate. Such units can provide a central supply system for an entire ward but have been superseded by completely independent single patient machines, each incorporating all monitors and fail-safe devices. They have facilities for disinfection by formalin or by the circulation of water heated to 90-95 C. The use of these machines has not unfortunately entirely eliminated the contamination of haemodialysis equipment with bacteria, which are probably derived from the water supply or from water softeners.

An autoclavable artificial kidney, which would clearly be of great value, has not yet been evolved, but work on this is being sponsored by the Scottish Working Party on Sterilization Methods.

\section{General Approach to Preventive Measures}

The significant hazard to staff health now associated with dialysis centres singles out the problem of infection control in these units from any other of recent years. In some areas the staffing of dialysis units is already a cause for concern, and may become more difficult with knowledge of the hepatitis risk. It would be easy under these circumstances to lose all sense of proportion and draw up unrealistically rigid codes of practice. Our ignorance of the hepatitis viruses, on the other hand, makes any scheme of preventive measures to some extent speculative. An attempt is made in what follows to apply to dialysis unit problems the general background of epidemiological thinking and experience derived from the study of other hospital outbreaks of communicable disease, and also such technical information as seems directly relevant or can be cited as fair analogy. Some general points are dealt with first.

(1) It is a commonplace of infection control in general hospitals that outbreaks of cross-infection usually occur in overcrowded wards, and this probably for several reasons. Efficient nursing is more difficult in cramped conditions. Pathways of transmission from the sources of infection to susceptible recipients are shorter. There is a greater likelihood of dangerous disseminators of infection being present and more patients to be infected. At a time when the social and other pressures towards overcrowding of dialysis unit beds are sometimes severe, the epidemiological argument against overcrowding is a strong one.

(2) Codes of practice for medical, nursing, and laboratory staffs are discussed in later sections. Far more difficult than drawing up regulations is the control of their day-to-day observance. Experience of infection control in other hospital wards shows that to maintain high morale and good ward discipline a good ward sister is indispensabie. We would strongly urge the appointment to every dialysis unit of a sister-in-charge of the highest calibre, who would be instructed in the microbiological aspects of unit management as well as in medical and other technical aspects.

(3) Members of the working party who have scrutinized haematology and biochemistry laboratory procedures from the standpoin: of infection control have been struck by such lapses from ordinary hygiene as the communal use of unplugged mouth pipettes, even by technicians with a solid background of bacteriological training. They would recommend that codes of practice drawn up for the safety of dialysis unit and laboratory personnel must be backed by practical instruction, perhaps with suitable film strips. The broad object of the instruction would be to demonstrate the application to the special context of the dialysis unit or the clinical laboratory of routine precautions used every day by the bacteriologist when he handles infected cultures.

(4) The preventive measures to be applied in the unit should be given an order of priority corresponding to the relative risks of infection likely to be associated with the various stages of the haemodialysis routine. The washing down of walls, for instance, while desirable on social grounds, is most unlikely to influence the incidence of hepatitis or other infections. Every possible effort should be made, on the other hand, to work out techniques that minimize the contamination of staff and environment with patients' blood.

(5) Particular stress should be laid in training on the importance in the present context of all that is subsumed under the heading of "personal hygiene." The term covers all " those preventive measures primarily within the responsibility of the individual, by which to promote health and to limit the spread of infectious diseases, mainly those transmitted by direct contact" (American Public Health Association, 1965). Good hygiene should be stressed for both staff and patients and includes baths or showers ; frequent hand-washing after going to the toilet or attending to patients and before meals ; keeping the hands, whether gloved or not, and contaminated articles away from the mouth, eyes, or other parts of the body; refraining from eating or smoking while at work; and protecting one's clothing with appropriate gowns. The practice of a high standard of hygiene is dependent on adequate hand-washing facilities, sluices, and toilets.

\section{Prevention of Hepatitis in Patients}

The prevention of hepatitis in dialysis unit patients clearly serves the interests of both patients and staff. Two main approaches to prevention that require discussion are (1) diminishing the patients' exposure to the causative viruses, and (2) prophylaxis with immunoglobulin.

\section{Exposure to Causative Viruses}

Patients may acquire infection from blood transfusions, from contaminated equipment, or by direct or indirect contact with other patients.

Transfusions.- There is a strong trend towards reducing the frequency of transfusions to patients with chronic renal failure for reasons other than the hepatitis hazard. When transfusions 
are considered necessary, some blood banks will issue blood collected from panels of known "safe" donors, provided the clinician gives adequate notice of his likely requirements.

Contaminated Equipment.-Dialysis equipment is presumably the main source of cross-infection with hepatitis viruses. This is supported by the lack of an association between hepatitis and peritoneal dialysis. Small-volume dialysers primed with saline rather than with blood carry a smaller risk of virus contamination. When possible, each patient should have his own artificial kidney; this would matter less if effective methods of sterilization became available. The problems of chemically disinfecting the artificial kidney are discussed below. As regards other equipment, an adequate supply of sterile, preferably disposable syringes is clearly essential.

Contact with Other Patients.-Patients undergoing chronic intermittent haemodialysis should be kept separate from those requiring acute short-term dialysis. How much contact is desirable between the patients in chronic dialysis units? First, it should be said that whatever its other advantages or drawbacks, home dialysis clearly diminishes the risk of hepatitis outbreaks. How much segregation should be aimed at in say a 10-bedded dialysis unit is more difficult to define with confidence in the present state of knowledge. Clearly patients who are suffering from acute hepatitis are best isolated in a separate room. Diagnosing hepatitis may, however, be far from simple in patients with renal failure unless regular routine serum alanine aminotransferase tests are being done on them. Whether all patients should have individual cubicle isolation is more debatable. Certainly, the transfer of infection from one patient to another will not be prevented by structural barriers alone, but will also depend on nursing morale and efficiency, barrier nursing procedures, adequate hand-washing, and sluice facilities.

\section{Immunoglobulin Prophylaxis}

The policy of immunoglobulin prophylaxis for dialysis unit patients is also bedevilled by our ignorance of virus hepatitis. Mirick, Ward, and McCollum (1965) found that routine administration of immunoglobulin after transfusions reduced the incidence of icteric post-transfusion hepatitis, but not the total incidence of hepatitis as shown by abnormal liver-function tests. As already mentioned above, the effectiveness of immunoglobulin prophylaxis has been denied in some episodes but not in others, possibly according to the nature of the causal virus concerned. Most clinicians would probably wish to give immunoglobulin to dialysis unit staff and patients when cases of icteric hepatitis were occurring. Whether it should be given routinely to patients at other times is a matter of opinion, particularly if a masked infection in a patient were considered to increase the risk to staff by diminishing the stringency of preventive measures. An attempt to assess the effectiveness of immunoglobulin in the dialysis unit context is at present being made by the Epidemiological Research Laboratory at Colindale.

\section{Prevention of Shunt Sepsis}

Protecting the patient from shunt sepsis raises a number of additional problems. The need for scrupulous asepsis during the insertion of the shunt has been stressed. There has been some discussion on whether dialysis units should include a minor operation room for shunt insertion or whether this should be done in the main theatre of the hospital. The competing arguments here are protection of the theatre staff, on the one hand, and, on the other, the provision of the best surgical facilities for a procedure the success of which is vital to longterm haemodialysis.

The prevention of shunt sepsis can clearly not be dissociated from infection control in the hospital as a whole. This will be particularly the case when an interchange of nursing staff occurs between the dialysis unit and other hospital wards. Again, if patients undergoing intermittent dialysis are routinely admitted to other wards for one reason or another, they will sooner or later acquire the epidemic strains circulating in the hospital.

As regards local protection of the shunt site against infection, the experience of surgical wards would suggest that one should aim at achieving a dry skin surface and a cumulative antibacterial effect from repeated disinfection of the patient's skin. For this purpose the range of choice includes hexachlorophane detergent preparations, iodophors like povidone-iodine, and aqueous or alcoholic solutions of chlorhexidine.

The topical use of Phenoxetol (phenoxyethanol) to combat pseudomonas infections is also worth bearing in mind. Martin et al. (1968) combined routine use of nasal antibacterial creams with local prophylactic measures at the shunt site. Finally, mention should be made here of a quite different approach to the prevention of shunt infections reported by Kopp, Grossmann, and Frey (1968). In the experience of these authors, liberal application to the shunt site and surrounding skin of a lanolin-based ointment containing neither antibiotics nor disinfectants completely prevented shunt infections and kept the skin soft and healthy.

Heparinization complicates the maintenance of a satisfactory shunt site because the margins of the shunt tend to ooze.

\section{Dialysis Unit Management and Hygiene}

The preventive measures designed to protect patients and staff from cross-infection should clearly be written into the procedural memoranda of the unit and not added as afterthoughts. The clinician in charge will therefore probably discuss his draft technical instructions with the local bacteriologist, virologist, and control of infection officer, so that the procedures recommended meet microbiological as well as clinical and other requirements. General and detailed guidance on infection control are given by Williams, Blowers, Garrod, and Shooter (1966). Certain topics of particular importance are dealt with below.

\section{Staff Health}

Stress has already been laid on the importance of good personal hygiene. Systematic records of staff health should be maintained, including details of minor illnesses such as mild gastrointestinal upsets. Muscle and joint pains were prominent early symptoms of hepatitis in the Stockholm outbreak. The medical officer in charge of the dialysis unit should be in touch with the doctor or doctors responsible for the health of hospital staff. Regular serum alanine aminotransferase tests on staff are done in some units and are to be recommended. Prophylactic immunoglobulin injections to the staff are indicated if infectious hepatitis is thought to be the cause of even a part of the dialysis unit hepatitis incidence in Britain. There is still no uniformity of opinion or practice on this point.

The unit should have an accident book for recording all minor mishaps to members of the staff while on duty, including finger-pricking, glass breakage, swallowing of potentially infected material, and splashes into the eye. A book of this kind will underline the importance of good technique; it may also provide valuable epidemiological evidence on the modes of transmission of hepatitis virus. Accident prevention should also be emphasized-for example, blood samples should be taken only when this is essential so as to minimize the risk of needle finger-pricks.

\section{Protective Clothing}

In principle an attempt must be made to block all routes by which the patients' blood, faeces, urine, and perhaps pharyngeal 
secretions could gain entry into the tissues of attendant staff through the skin, mouth, respiratory tract, or eye. This may seem a formidable undertaking, but in practice there are certain times at which particular care is required. Every effort should be made to devise a most careful routine for (1) putting the patient on and off the dialyser, (2) dealing with sudden haemorrhage or blood spillage, (3) dismantling equipment for disinfection and cleaning, and (4) dealing with patients' excreta while dialysis is under way.

As regards protective clothing, it should be remembered that the main purpose of wearing gowns, caps, masks, and gloves in operating-theatres is protection of the patient's wound from organisms liberated by the surgeon or nursing staff. The wearing of similar clothing for self-protection should be considered critically before it is unreservedly approved.

Protection of the hands with gloves is certainly desirable for the medical and nursing staff at certain stages of the dialysis procedure, particularly when the patient is going on and off the artificial kidney. Swedish workers are in no doubt that gloves are essential and effective. While necessary, the wearing of gloves is by itself not sufficient, and various problems remain. The blood-contaminated gloves may in turn contaminate the wearer's face or clothing or various surfaces unless this risk is borne in mind. Rinsing the blood-contaminated gloved hand in a hypochlorite solution containing 1,000 p.p.m. of available chlorine should help to dilute a potential inoculum of virus and to inactivate it. Three further points regarding gloves may be mentioned. Firstly, a proper allocation of duties to a twoperson team should be considered from the standpoint of staff protection, as already practised in the daily routine for the dressing of surgical wounds. Secondly, the ordinary rubber glove is uncomfortable to wear for long periods of the order required for routine haemodialysis. Thirdly, some alternative hand-protection in the event of a sudden crisis not providing the time needed to don gloves would be useful.

A strong case could be made for wearing a mask, goggles, and protective gown at any time when the wearing of gloves is important. Some form of transparent headgear could perhaps be devised that offered protection to the eyes, face, and mouth of the nurse without interposing a psychological barrier between her and the patient. An alternative protection to the eyes is the wearing of spectacles of plain glass.

\section{Disposal of Contaminated Articles}

The unit will need an adequate supply of waste bins, pedal bins, and plastic or fabric bags of various kinds to deal with contaminated materials whether for ordinary refuse disposal, incineration, autoclaving, or laundering. Bins should always contain polyethylene or heavy paper bags to receive waste, so that bags and contents are incinerated together. Policy on the laundering of fabrics from the unit will depend on local thinking on the safe handling of contaminated materials in the hospital laundry.

\section{Disinfection}

Only certain physical methods such as heat or ionizing radiations can be relied on to kill all microbes. Chemical disinfectants should therefore be used only when physical methods are impracticable. When chemicals are used scrupulous cleanliness of the equipment concerned is a necessary prerequisite to adequate disinfection.

Antimicrobial agents are used in dialysis units for a number of separate purposes. Unfortunately little information is available on the resistance of the hepatitis viruses to disinfection, and fully reliable methods even for dealing with bacterial contamination are not yet available. The comments that follow arz therefore still somewhat tentative.

\section{Disinfection of Equipment after Use}

One important objective of disinfection is to protect patients and staff, and especially those who dismantle, clean, and reassemble the apparatus, from infection with hepatitis virus. As this virus is not available for testing, any advice given must be based on experience with other viruses. It should be said that techniques for washing back residual blood as completely as possible into the patient at the end of haemodialysis will clearly diminish the potential virus contamination to be dealt with (Evans, Clarkson, and Curtis, 1967).

The P.H.L.S. Committee on the Testing and Evaluation of Disinfectants (P.H.L.S., 1965) was of the opinion that such evidence as was available for other viruses pointed to the halogens or pure phenol as the most active virucidal disinfectants Phenol is expensive and toxic. Reports (unpublished) of experiments specially made by Dr. Yvonne Cossart using poliovirus as a model confirmed the efficacy of hypochlorite but failed to show any activity with an iodophor. To disinfect equipment after haemodialysis, therefore, the logical suggestion at present is that a hypochlorite detergent solution be used, either as an ad hoc mixture of a commercially available hypochlorite solution-for example, Chloros or Domestos-with a compatible detergent (see Hospital Equipment Information 16/66) or as a specially prepared mixture such as Diversol BX. It is not easy to recommend any particular concentration. Naked microorganisms are rapidly killed by a very few p.p.m. of available chlorine, but this is equally rapidly inactivated by organic matter. The higher concentrations commonly used are purely to ensure that some chlorine remains available. In practice solutions containing 1,000 to 10,000 p.p.m. are used. It is not clear to what extent these concentrations cause damage to materials, but this can be reduced by using a relatively short exposure of up to 30 minutes.

A rough check on the adequacy of concentration can be made by estimating the available chlorine left in the working solution at the end of the disinfection period. Virtually any detectable chlorine level can be regarded as satisfactory. It must be emphasized that hypochlorite solutions have only a limited life at use dilutions as well as being readily inactivated by organic matter. Use dilutions must therefore be made up afresh for each disinfecting operation. Furthermore, because hypochlorite is as rapid in action as it is in being inactivated, the solution should not be allowed to remain in contact with the items to be disinfected for more than a relatively short time, such as 30 minutes. The storage of apparatus for hours or days in the same chlorine solution in which they have been disinfected may be dangerous, as the fluid may well have become a culture of micro-organisms. Chlorine damage to the skin of staff may be prevented by the use of protective clothing, and by rinsing the hands in a neutralizing solution of dilute acid and/or thiosulphate. Formaldehyde and glutaraldehyde are also active against viruses in suitable concentration but have various drawbacks in the present context.

\section{Other Aspects}

(1) To render any piece of equipment as nearly sterile as possible before use, physical methods are preferred when possible. Ultimately, autoclavable or disposable circuits will simplify the problems of dialysis units. Meanwhile gammairradiation of membranes and of other plastic components has been used. Experiments with low-temperature steam would be worth doing, particularly in conjunction with formalin vapour. Ethylene oxide has been used but requires special equipment and careful monitoring, and residual gas must be removed. Experimental work on the use of ethylene oxide for disinfecting haemodialysis equipment is in progress at a number of centres. We have had reports on the use of various liquid agents-for example, formalin at concentrations up to $30 \%$, Portex, Diversol BX, and Chloros. At present it is not possible to give 
firm recommendations, as most units have reported unexpected failures with seemingly adequate concentrations of disinfectant.

(2) Several units have reported a gradual build-up of bacterial contamination in dialysis fluid. The organisms are probably derived from the water supply or from water-softening equipment. Experiments with in-line filters for continuously removing bacteria from dialysis fluid have given promising results.

(3) For hand hygiene of patients and staff the mechanical and diluting effect of frequent hand-washing is important. None of the agents already recommended for the hygiene of shunt sites is likely to be virucidal, and when such an agent is considered necessary rinsing in hypochlorite of a chlorine concentration of say 200 p.p.m. is perhaps the best that can be suggested.

(4) Skin sensitization from disinfectants has been reported by several units and can be a problem. Excessive use of concentrated solutions of Tego compounds with or without added formalin has given rise to dermatitis in nursing staff. One unit has reported reactions in patients to topical application of aqueous chlorhexidine.

(5) When a steam jet washer or boiler for bedpans is not available, faeces from patients undergoing haemodialysis should be covered with a suitable phenolic disinfectant before being discharged to waste. Kelsey and Maurer (1967) have made recommendations on the appropriate use dilutions of available disinfectants in this group.

\section{Bacteriological Monitoring of Equipment}

Routine bacterial counts on samples from the dialysis fluid circuit are essential for control of the disinfection methods being practised in the unit. Firm guidance cannot be given at present on the best culture media or temperatures of incubation, or on the identification of the saprophytic organisms isolated. A simple method for direct culturing of dialysis fluid samplesfor example, by a technique analogous to the dip-slide culture method for urine (Guttmann and Naylor, 1967)-would be of use.

\section{Protection of Laboratory Staff}

The following are the main categories of laboratory test required on dialysis unit patients:

Biochemical.-Pre- and post-dialysis estimations of blood electrolytes, urea, proteins. Osmometry for measuring osmolality. Tests of dialysis fluid for urea, etc.

Haematological.-Cross-matching of blood. Haemoglobin estimations and sometimes more detailed tests. Clotting-times in
heparinized patients.

Bacteriological.-Blood cultures. Swabs from shunt sites. Bacterial counts on dialysis fluids. Tests on disinfection procedures.

At some centres the establishment of a special laboratory to deal solely with dialysis unit tests has been discussed. The advantage of such a laboratory would simply be to limit the health hazard to one or a few technicians. The drawbacks seem to outweigh this one advantage. These include dissipation of laboratory resources, a lower standard of technical work unless the special laboratory is a multi-disciplinary one, and the administrative problem of directing specimens to different places. Most pathologists would prefer to designate special senior technical staff in their own laboratories to deal with specimens thought to present a hazard, and otherwise simply to review biochemical and haematological techniques so as to include the kind of precautions routinely practised in microbiological laboratories. It must be said, however, that adequate microbiological precautions are difficult to apply when bench space
is very restricted.

Perhaps the main problem in busy and usually overcrowded laboratories is to decide how comprehensive the range of pre- cautions should be. Some may consider there is no strong case for serious concern, but in the Stockholm outbreaks discussed by Ringertz and Nyström (1967) 24 laboratory workers were affected. Laboratory workers are doubtless continuously exposed to the hepatitis hazard, though perhaps until recently in less concentrated form than dialysis unit material seems to provide. The best compromise would seem to be to concentrate on a few fundamental precautions based on probable major risks rather than to lay down highly elaborate rituals that may not be observed.

Most biochemistry and haematology laboratory technicians, certainly most of the senior ones, will have had some bacteriological teaching and experience during their training. They will simply need a reminder that by and large they should observe basic microbiological precautions when doing biochemical or haematological tests on dialysis unit specimens. Reminded that blood from a dialysis unit patient may be more dangerous than a stool from a typhoid patient, they will realize what precautions are desirable. Science graduates in biochemistry may be more vulnerable in this regard.

\section{Likely Sources of Risk}

It is suggested that a brief training course should be given by the hospital bacteriologist, stressing some of the major likely sources of risk, as listed below.

(1) Specimens of blood from dialysis unit patients should be readily recognizable on arrival in the laboratory. They may be sent in specially marked containers and/or enclosed in individual plastic bags. In one unit the blood is centrifuged in its plastic bag and the supernatant taken off with a Pasteur pipette into a fresh screw-cap bottle enclosed in another plastic bag. The value of the plastic bag is perhaps debatable. If the outside of the bottle is contaminated with blood, the bag may well be contaminated also; if not, the bag may not be necessary.

(2) The risks of centrifuging, of aerosol formation, and of breakages in the centrifuge should be explained and appropriate preventive measures discussed.

(3) Whether gloves should be worn by laboratory staff or reliance placed on a good no-touch technique is perhaps debatable. A combination of standard microbiological techniques, adequate handwashing, and judicious use of squares of polyethylene film might obviate much of the risk of contact with blood. It is probably more realistic to suppose that, particularly in busy clinical laboratories, adequate precautions will not always be taken and to encourage the wearing of disposable gloves, especially during the preliminary separation of serum for biochemical tests.

(4) The practice of mouth pipetting, sometimes with unplugged pipettes that may be used by numerous workers in succession, strikes the bacteriologist observing biochemistry and haematology procedures as highly unhygienic. It has been said that for precise measurement of small volumes of blood, mouth pipetting is essential. Present methods for measuring small volumes of serum for biochemical tests may involve two hazards-namely, mouth pipetting and wiping of the tips of pipettes with cotton-wool to remove excess blood. Every effort should be made to substitute for these old-fashioned procedures methods that do not call for direct mouth pipetting.

(5) However crowded and busy the laboratories may be, the safe disposal of contaminated pipettes and other glassware into suitable containers for autoclaving should present no greater problems in haematology and biochemistry laboratories than in bacteriological departments. Wastes from autoanalysers should drip into containers with disinfectant and not directly into sinks.

(6) Dialysis membranes of autoanalysers should not be changed with ungloved hands.

(7) Progressive automation of biochemical procedures may reduce hazards to staff-for example, by avoidance of mouth pipetting. More knowledge is needed, however, on the microbial contamination of autoanalysers when infected specimens go through.

(8) The design of certain blood containers, notably of the small plastic containers with push-in stoppers used for oxalated or fluoride blood samples is very unsatisfactory. Contamination of the hands is almost inevitable during removal of the stopper. Screw-capped $\frac{1}{2}-0 z$. (14-ml.) or 1-oz. (28-ml.) bottles are far safer to handle. 


\section{Discussion}

The foregoing comments and recommendations on the hygiene of haemodialysis units are tentative and point the need for further work in this field. The clinical, engineering, and microbiological problems posed by these units call for interdisciplinary study. In particular, hospital bacteriologists should squarely accept responsibility for giving advice and practical help on the disinfection and monitoring of the machines now in use, and on the associated problems of cross-infection in dialysis unit patients and staff. We would also strongly recommend that physicians and surgeons dealing with increasingly sophisticated new medical and surgical procedures should consult their bacteriological colleagues at an early stage on the planning and management of units in which problems of crossinfection may arise.

\section{REFERENCES}

American Public Health Association (1965). Control of Communicable Diseases in Man, 10th ed. New York.

Brescia, M. J., Cimino, J. E., Appel, K., and Hurwich, B. J. (1966). New Engl. F. Med., 275, 1089

Curtis, J. D. (1967). Hosp. Med., 1, 295.

Curtis, J. R., and Eastwood, J. B. (1968). Brit. med. F., 1, 484

Curtis, J. R., and Eastwood, J. B. (1968). Brit. med. 7., 1, 484. 1 st International Symposium, Paris, p. i54. Lucerne.

Dalla Rosa, C., Galanti, G., Ancona, G., Bruschi, E., and Confortini, P. (1967). Proceedings of the European Dialysis and Transplant Association III, Excerpta Medica International Congress Series, No. 131, p. 107. Amsterdam.

Drukker, W., Alberts, C., Odé, A., Roozendaal, K. J., and Wilmink, J. (1967). Proceedings of the European Dialysis and Transplant Association III, Excerpta Medica International Congress Series, No. 131, p. 90. Amsterdam.
Drukker, W., Jungerius, N. A., and Alberts, C. (1968). Proceedings of the European Dialysis and Transplant Association IV, Excerpta Medica International Congress Series, No. 155, p. 3. Amsterdam.

Eastwood, J. B., and Curtis, J. R. (1968). Brit. med. F., 1, 486.

Evans, D. B., Clarkson, E. M., and Curtis, J. R. (1967). Brit. med. F., 4, 651.

Guttmann, D., and Naylor, G. R. E. (1967). Brit. med. 7., 3, 343.

Kääräinen, L., Klemola, F., and Paloheimo, J. (1966). Brit. med. F., 1,

Kidd, E. E. (1964). Brit. med. F., 1, 880.

Kelsey, J. C., and Maurer, I. M.' (1967). Mth. Bull. Minist. Hlth Lab. Serv., 26, 110.

Kopp, K. F., Grossmann, D. F., and Frey, J. (1968). Proceedings of the European Dialysis and Transplant Association IV, Excerpta Medica International Congress Series, No. 155, p. 373.

Krugman, S., Giles, J. P., and Hammond, J. (1967). F. Amer. med. Ass., 200,365 .

Kunin, C. M. (1967). Ann. intern. Med., 67, 151.

McDonald, H. P., Friedman, E. A., Waterhouse, K., and Thomson, G. E. (1967).' Proceedings of the European Dialysis and Transplant Association III, Excerpta Medica International Congress Series, Association III, Excerpta M
No. 131, p. 111. Amsterdam.

Martin, A. M., Clunie, G. J. A., Tonkin, R. W., and Robson, J. S. (1968). Proceedings of the European Dialysis Transplant Association IV, Excerpta Medica International Congress Series, No. 155, p. 67. Amsterdam.

Mirick, G. S., Ward, R., and McCollum, R. W. (1965). New Engl. F. Med., 273, 59 .

Pendras, J. P., and Erickson, R. V. (1966). Ann. intern. Med., 64, 293.

Public Health Laboratory Service (1965). Brit. med. F., 1, 408.

Quinton, W. E., Dillard, D. H., and Scribner, B. H. (1960). Trans. Amer. Soc. artif. intern. Organs, 6, 104.

Ringertz, O., and Melén, B. (1966). Lancet, 1, 151

Ringertz, O., and Nyström, B. (1967). Scand. f. Urol. Nephrol., 1, 192

Ringertz, O., and Zetterberg, B. (1967). New Engl. F. Med., 276, 540.

Shaldon, S. (1966). Postgrad. med. 7., 42, November Suppl.

Sherris, J. C., Cole, J. J., and Scribner, B. H. (1961). Trans. Amer. Soc. artif. intern. Organs, $7,37$.

Smith, D. R. (1964). Brit. med. F., 1, 945.

Stille, W., Brass, H., Hach, W., Renner, D., and Heintz, R. (1967). Dtsch. med. Wschr., 92, 467.

Williams, R. E O, Blowers, R., Garrod, L. P., and Shooter, R. A. (1966). Hospital Infection-Causes and Prevention, 2 nd ed. London.

\title{
Arterial Blood Gas Tensions and $\mathrm{pH}$ in Acute Asthma in Childhood
}

\author{
H. SIMPSON,* M.B., M.R.C.P.ED., D.C.H., D.OBST.R.C.O.G. \\ J. O. FORFAR, $\dagger$ M.C., M.D., B.SC., F.R.C.P., F.R.C.P.ED., D.C.H. \\ D J. GRUBB, $\ddagger$ M.B., F.F.A. R.C.S.
}

Brit. med. F., 1968, 3, 460-464

\begin{abstract}
Cummary : Studies of the arterial blood gas tensions and $\mathrm{pH}$ in 21 children during 24 acute attacks of asthma showed that all were hypoxic on admission to hospital, and in 10 there was evidence of carbon dioxide retention. Cyanosis, invariably present when the $\mathrm{So}_{2}$ was below $85 \%$, and restlessness in patients breathing air were the most reliable indices of the severity of hypoxia. There were no reliable clinical guides to the $\mathbf{P c o}_{2}$ level. Conventional oxygen therapy in tents $(25-40 \%)$ did not always relieve hypoxia, and in three cases the administration of oxygen at a concentration of $40 \%$ or over failed to produce a normal arterial oxygen tension. Uncontrolled oxygen therapy may aggravate respiratory acidosis, and three of our patients developed carbon dioxide narcosis while breathing oxygen. The necessity for blood gas measurements in the management of severe acute asthma in childhood is emphasized.
\end{abstract}

\section{Introduction}

The arterial blood gas tensions in bronchial asthma in adults have been the subject of several recent reports (Rees, 1966;

\footnotetext{
- Lecturer in Child Life and Health.

+ Professor of Child Life and Health

$¥$ Consultant Anaesthetist.

Department of Child Life and Health, University of Edinburgh, and the Royal Hospital for Sick Children, Edinburgh.
}

Waddell et al., 1967 ; Tai and Read, 1967; Palmer and Diament, 1967). The situation in childhood asthma is not so well studied despite the evidence that respiratory failure is not uncommon (Tsuchiya and Bukantz, 1965 ; Downes and Wood, 1965) and death by no means rare in status asthmaticus in children (Lanoff and Crawford, 1964 ; Richards and Patrick, 1965). In addition, there has been the increase in mortality from asthma at all ages, most pronounced at ages 10-14 years (Speizer et al., 1968).

In severe asthma in adults respiratory acidosis may be aggravated by injudicious oxygen therapy (Schiller et al., 1951), but the importance of this potential danger in children with severe acute asthma is uncertain. We report here the clinical features and arterial blood gas findings in 21 children studied during 24 acute exacerbations of asthma and describe the response to therapy, in particular the administration of oxygen.

\section{Patients and Methods}

The patients (12 males and 9 females) ranged in age from 2 to 12 years and were admitted to the Royal Hospital for Sick Children, Edinburgh, between September 1965 and December 1967. Clinical details on admission are summarized in Table I. Case 1 was studied on two separate admissions and Case 2 on three. The severity of asthma was graded according to the classification of Kraepelien et al. (1958), grade I consisting of 